\title{
Respiratory morbidity in Merseyside schoolchildren exposed to coal dust and air pollution
}

Bernard Brabin, Mary Smith, Paul Milligan, Christopher Benjamin, Eithne Dunne, Michael Pearson

\begin{abstract}
A cross sectional study was carried out to determine whether schoolchildren in a specific locality exposed to pollution from steam coal dust have an excess of respiratory symptoms compared with children in control areas.
\end{abstract}

A total of 1872 primary schoolchildren (aged 5-11 years) from five primary schools in the Bootle dock area of Liverpool (exposed area), five primary schools in South Sefton (control area), and five primary schools in Wallasey (control area) were studied. A questionnaire was distributed through the schools and was completed by the parents of the children. The questionnaire inquired about respiratory symptoms (cough, wheezing, and shortness of breath), allergy, atopy, smoking, and socioeconomic factors. Height, weight, and peak expiratory flow were measured.

Compliance was good $(92 \%)$ and similar in the three study areas. The children in the three areas were of similar mean age ( 7.5 years), height $(1.24 \mathrm{~m})$, sex ratio, and had a similar prevalence of paternal $(6 \cdot 2 \%)$ and maternal $(7 \%)$ asthma. The exposed zone contained more unemployed parents $(41,29$, and $29 \%$ respectively), more rented housing $(64,45,34 \%)$, and more smoking parents $(71,60,59 \%)$ than the control areas. Respiratory symptoms were significantly more common in the exposed area, including wheeze $(25 \cdot 0,20 \cdot 6$, and $17 \cdot 5 \%)$, excess cough $(40 \cdot 0,23 \cdot 4$, and $25 \cdot 1 \%)$, and school absences for respiratory symptoms $(47 \cdot 5,35 \cdot 9$, and $34 \cdot 9 \%)$. These differences remained significant even if the groups were subdivided according to whether or not parents smoked or were employed. Multiple logistic regression analysis confirmed the exposed zone as a significant risk factor for absenteeism from school due to respiratory symptoms (odds ratio $1 \cdot 55,95 \%$ confidence interval $1 \cdot 17$ to $2 \cdot 06$ ) after adjusting for confounding factors. Standard dust deposit gauges on three schools confirmed a significantly higher dust burden in the exposed zone.

An increased prevalence of respiratory symptoms in primary schoolchildren exposed to coal dust is confirmed. Although the association with known coal dust pollution is suggestive, a cross sectional study cannot confirm a causal relation and further studies are needed. (Arch Dis Child 1994; 70: 305-312)

There is a growing public and scientific awareness of the impact of asthma and allergies on health in terms of morbidity. In recent years increases in the prevalence of asthma have been reported in some countries and differences have been observed between regions and countries. ${ }^{1-4}$ Possible explanations for these variations include changes in the treatment of allergic disease, diagnostic labelling, the use of medical care, or risk factors such as air pollution conditioning prevalence or severity. ${ }^{56}$ A large international study in eight European countries of chronic respiratory diseases in children in relation to air pollution coordinated by the World Health Organisation clearly showed an association between air pollution and various respiratory indices in children (cough, shortness of breath, bronchitis). ${ }^{7}$ Of the two air pollutants studied smoke appeared to have a far greater effect than sulphur dioxide. Wheezing was not associated with smoke or sulphur dioxide concentrations. More recent research has implicated total suspended air particles as an important contributory cause of respiratory symptom episodes in children. ${ }^{8} 11$

Air pollution with substances known to be allergenic has been shown to be a cause of asthma. Whether air pollution from substances not known to be allergenic or directly irritant to the airways can lead to an increased incidence of asthmatic symptoms or altered bronchial hyperreactivity is not known, however, nor is it established whether any effects apply to everyone or to specific subsets of the population such as children with an atopic diathesis. ${ }^{12} 13$ Sultz et al have reported a significant correlation between levels of air pollution and the number of children admitted to hospital with asthma in Buffalo, USA. ${ }^{14}$

In Liverpool in 1991 an opportunity arose to compare the effect of an increased environmental dust burden in a specific locality with unaffected areas in the same city. In the first part of 1988 a bulk handling facility on the Liverpool docks began importing first petroleum coke and later steam coal for various uses including local power stations. The coal was unloaded by mechanical grabs, stockpiled on the docks for variable periods, and then transferred to either rail or road wagons for transportation. The volume of coal/petroleum 


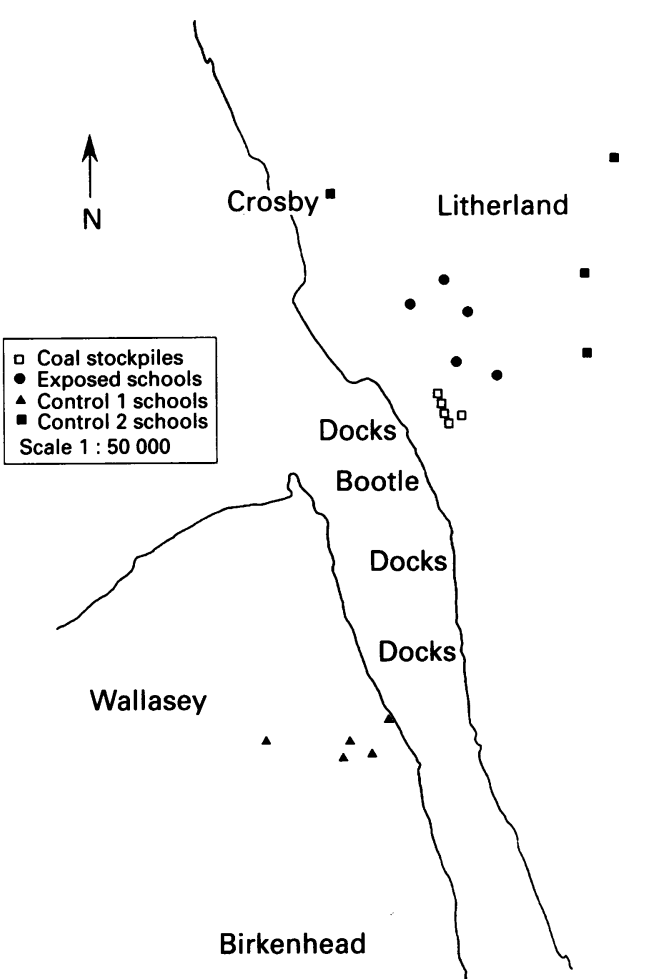

Location of schools in exposed and control areas.

coke in $1988-9$ was 0.5 million tonnes, increasing to nearly 2 million tonnes in 1991-2. The local council had received over 600 complaints about dust nuisance by April 1991, almost all from residents living within 1-2 km of the coal terminal. A group of parents and teachers produced an uncontrolled survey from the school nearest to the dock $(<500 \mathrm{~m})$ which suggested a high incidence of 'asthma' and inhaler usage, and a preliminary audit of general practice attendance ${ }^{15}$ reported an increase in self reported ill health but this did not seek to ascertain if specific problems occurred in children. In response a steering committee was established to investigate whether there was an increased prevalence of respiratory symptoms in the 'affected area' and, if so, whether this was due to known factors or could be the result of pollution.

\section{Subjects and methods}

DESIGN

A cross sectional survey of respiratory symptoms in primary schoolchildren (5-11 years) was designed to determine the prevalence of respiratory symptoms in the exposed area compared with two control areas in Merseyside of similar socioeconomic status. All three areas were recognised to have major housing and unemployment problems and it was thought before the study that these were of similar order.

DEFINING THE STUDY POPULATIONS

Coal dust exposed group (exposed)

This group consisted of children residing in and attending the five primary schools geographically proximate to the coal handling terminal (figure) and including the area from which the nuisance dust complaints had come. They ranged from 0.5 to $2 \mathrm{~km}$ distance from the terminal. These were the only primary schools located within this area.

Control group 1

Children attending five primary schools 5-8 $\mathrm{km}$ southwest of the terminal and thus upwind of the prevailing winds were included in this group. This is dockland area on the other side of the River Mersey, but the docks are now largely non-operational.

\section{Control group 2}

This group consisted of children attending five primary schools in an area $3-8 \mathrm{~km}$ from the coal terminal. There were no complaints of coal dust nuisance from residents of this area and it is beyond the projected limit for the dispersion of dust emanating from the docks.

\section{QUESTIONNAIRE}

A questionnaire was sent to parents and distributed through the primary schools. It was adapted and modified from a new questionnaire designed by Clifford et al. ${ }^{16}$ This questionnaire had been tested in Southampton and Birmingham and had a high response rate $(84 \%)$; it was found to be highly repeatable with respect to current symptoms. This questionnaire, with slight modifications, was pilot tested among several households in the exposed area and parental suggestions considered in designing the final format. In particular, the layout and style were made easier for lay people to understand and questions were added about socioeconomic factors in the home, attitudes to the coal and grain terminals on the docks, and about school absences for respiratory symptoms. The study questionnaire includes questions on several factors related to the risk of asthma. These include: type of dwelling (construction, carpets, dampness); type of heating; furred pets in the house currently and previously; parental smoking at the time of the study and previously; type of infant feeding; and family history of allergy. This allows risk factors for respiratory morbidity other than air pollution to be assessed.

Wheeze and dyspnoea were identified by the questions: 'Has your child ever had an attack of wheezing (by wheezing, I mean noisy breathing and a whistling sound coming from the chest not the throat)?' and 'Has your child ever been either unexpectedly breathless at rest or more breathless than you would expect after exercise (by breathless, I mean out of breath or puffed)?' Questions used to identify abnormal cough were 'Has your child ever seemed to cough more (or to get more coughs) than other children?' Morbidity was assessed using questions related to hospital admission and school absenteeism due to respiratory symptoms. Socioeconomic information was requested related to housing and employment. Questions relating to croup and hay fever were included 
for completeness and also as controls as they are not typical of asthma.

\section{QUANTIFICATION OF AIR POLLUTION}

The local authority collected dust level measurements using British Standard dust deposit gauges as part of a separate environmental assessment of the area between December 1990 and November 1991. Monitoring was carried out using a four weekly sampling period. During the school survey further British Standard dust deposit gauges were set up on a single school roof in each of the study areas and collected samples were analysed following British Standard guidelines.

\section{SAMPLE SIZE, EXCLUSIONS, AND STATISTICAL ANALYSIS}

We wanted to estimate the differences in prevalence of respiratory symptoms due to environmental exposure between two groups (either groups 1 and 2, or 1 and 3, or 2 and 3), where no reasonable estimates of exposure risk for the groups were available. An estimate with an expected prevalence of $10 \%$ and relative risk of 1.5 with $90 \%$ power requires 525 in each group. To ensure a representative sample five primary schools were enrolled for each study area. There were a total of 4084 children in the 15 survey schools and thus the questionnaires were distributed to every second child, assuming $75 \%$ compliance on questionnaire completion. Statistical analyses

Table 1 Prevalence of socioeconomic variables in control and exposed groups. Values are $\%$ (number)

\begin{tabular}{|c|c|c|c|c|c|}
\hline \multirow[b]{2}{*}{ Variable } & \multirow[b]{2}{*}{ Control 1} & \multirow[b]{2}{*}{ Control 2} & \multirow[b]{2}{*}{$\begin{array}{l}\text { Exposed } \\
\text { area }\end{array}$} & \multicolumn{2}{|c|}{ Significance ( $p$ value) } \\
\hline & & & & $\begin{array}{l}\text { Exposed } \mathrm{v} \\
\text { control area } 1\end{array}$ & $\begin{array}{l}\text { Exposed } \mathrm{v} \\
\text { control area } 2\end{array}$ \\
\hline Maternal employment & $46 \cdot 6(646)$ & $42 \cdot 5(633)$ & $27 \cdot 4(121)$ & $<0.001$ & $<0.001$ \\
\hline Paternal employment & $71 \cdot 1(564)$ & $71 \cdot 0(558)$ & $59.5(363)$ & $<0.001$ & $<0.001$ \\
\hline Rented home & $34 \cdot 2(669)$ & $44.9(648)$ & $64 \cdot 5(462)$ & $<0.001$ & $<0.001$ \\
\hline Damp house & $15 \cdot 6(652)$ & $11 \cdot 8(645)$ & $21 \cdot 4(448)$ & $<0.25$ & $<0.001$ \\
\hline Smokers in house & $58 \cdot 6(679)$ & $60 \cdot 3(675)$ & $70 \cdot 6(476)$ & $<0.001$ & $<0.001$ \\
\hline Pet in house & $63 \cdot 2(688)$ & $50 \cdot 1(659)$ & $54 \cdot 4(471)$ & $<0.01$ & NS \\
\hline
\end{tabular}

NS $=$ not significant at $5 \%$ level.

Table 2 Respiratory variables in control and exposed groups. Values are \% (number)

\begin{tabular}{|c|c|c|c|c|c|}
\hline \multirow[b]{2}{*}{ Variable } & \multirow[b]{2}{*}{$\begin{array}{l}\text { Control } \\
\text { area } 1\end{array}$} & \multirow[b]{2}{*}{$\begin{array}{l}\text { Control } \\
\text { area } 2\end{array}$} & \multirow[b]{2}{*}{$\begin{array}{l}\text { Exposed } \\
\text { area }\end{array}$} & \multicolumn{2}{|c|}{ Significance ( $p$ value) } \\
\hline & & & & $\begin{array}{l}\text { Exposed } \mathrm{v} \\
\text { control } \\
\text { area } 1\end{array}$ & $\begin{array}{l}\text { Exposed } \mathrm{v} \\
\text { control } \\
\text { area } 2\end{array}$ \\
\hline Ever diagnosed asthma & $17 \cdot 0(675)$ & $15 \cdot 3(675)$ & $21 \cdot 1(474)$ & NS & $<0.025$ \\
\hline Ever diagnosed bronchitis & $11 \cdot 0(665)$ & $9 \cdot 5(653)$ & $16 \cdot 5(462)$ & $<0.01$ & $<0.001$ \\
\hline Ever diagnosed croup & $14 \cdot 1(665)$ & $12 \cdot 3(653)$ & $14 \cdot 2(458)$ & NS & NS \\
\hline Well controlled asthma ${ }^{\star}$ & $82 \cdot 3(124)$ & $87 \cdot 8(115)$ & $72 \cdot 1(111)$ & NS & $<0.01$ \\
\hline Maternal asthma & $7 \cdot 7(660)$ & $5.9(641)$ & $7 \cdot 5(452)$ & NS & NS \\
\hline Paternal asthma & $5 \cdot 5(633)$ & $6 \cdot 1(642)$ & $7 \cdot 1(439)$ & NS & NS \\
\hline Attack of wheezing & $20 \cdot 6(656)$ & $17 \cdot 5(644)$ & $25 \cdot 0(448)$ & NS & $<0.01$ \\
\hline Attack of breathlessness & $11 \cdot 2(663)$ & $10 \cdot 2(650)$ & $19 \cdot 1(451)$ & $<0.001$ & $<0.001$ \\
\hline Excess cought & $25 \cdot 1(686)$ & $23.4(670)$ & $40 \cdot 0(480)$ & $<0.001$ & $<0.001$ \\
\hline \multicolumn{6}{|l|}{ Ever admitted to hospital } \\
\hline \multicolumn{3}{|l|}{ Absent from school for } & $8 \cdot 2(408)$ & NS & $<0.001$ \\
\hline respiratory symptoms & $34.9(642)$ & $35.9(638)$ & $47 \cdot 5(453)$ & $<0.001$ & $<0.001$ \\
\hline Allergies, eczema, or hay fever & $16.7(610)$ & $12 \cdot 7(612)$ & $13.6(427)$ & NS & NS \\
\hline All drugs prescribed & $13 \cdot 8(675)$ & $10 \cdot 7(663)$ & $17 \cdot 7(468)$ & NS & $<0.001$ \\
\hline Antiasthmatic drugs & $9.9(675)$ & $6 \cdot 2(663)$ & $11 \cdot 7(468)$ & NS & $<0.001$ \\
\hline
\end{tabular}

NS $=$ not significant at $5 \%$ level.

^Proportion of those with asthma in whom it was well controlled.

†Child who seems to cough more (or get more coughs) than other children

łAbsent for one or more days in preceding 12 months. were performed using EpiInfo and the Statistical Package for Social Sciences (SPSS).

\section{PROJECT SCHEDULE AND IMPLEMENTATION}

The questionnaires were distributed to each school's headteacher in September 1991 and the surveys were completed concurrently in the three study areas between October and December. Questionnaires were delivered to the schools and given to every second child in each class based on alphabetical order. Children returned them to the class teacher when they had been completed. Class lists were made available by headteachers to enable compliance to be calculated. Absentees were seen at revisits scheduled within two weeks of the initial survey. Informed consent was requested from parents to measure the height, weight, and peak respiratory flow of all children.

Air pollution gauges were placed during the months of December 1991-April 1992. The study protocol was approved by the ethical committee of the district health authority and the education authorities for the study areas.

\section{Results}

\section{STUDY POPULATIONS}

A total of $1872(92.0 \%)$ questionnaires were returned out of 2035 sent to parents. Of these, $78.5 \%$ were completed by the mother, $4.8 \%$ by the father, and $15.8 \%$ by both parents. The response rates in the three study areas were similar. In particular, the two schools in the exposed area from which complaints were made about the risk of asthma and coal dust exposure showed comparable compliance figures to other schools (92 and 99\%).

There were significant socioeconomic differences between the exposed and control zones. Parental unemployment, the proportion of housing that was rented or was damp, and the proportion of smoking parents were all significantly higher in the exposed area (table 1). The mean height, weight, age, and sex ratio were not different, however. Peak expiratory flow adjusted for height was similar between the three areas and was not different from the mean predicted values standardised for height ${ }^{17}$ (mean (SD) values ( $1 / \mathrm{min}$ ): exposed area 242 (69); control 1, 225 (72); and control 2, $238(69))$.

Children from the exposed zone had a lower mean (SD) birth weight (g) than children from either control area (exposed 3250 (600); control 1, 3290 (57); control 2, 3350 (600)). They were also reported to have been breast fed for a shorter period (months) (exposed 4.0 (3.4) (SD) months; control 1, 4.5 (4.5); control $2,4.6(4.5))$. As there was no significant difference between the two control areas this offered the opportunity to pool the control data for some of the subsequent analyses.

\section{RESPIRATORY SYMPTOMS}

The whole group comparisons show that there was a significantly increased prevalence of most 
Table 3 Compliance and respiratory indices (\%) in individual schools

\begin{tabular}{|c|c|c|c|c|c|c|c|c|c|c|c|c|c|c|c|}
\hline \multirow[b]{2}{*}{ Variable } & \multicolumn{5}{|c|}{ Control area 1} & \multicolumn{5}{|c|}{ Control area 2} & \multicolumn{5}{|c|}{ Exposed area } \\
\hline & 1 & 2 & 3 & 4 & 5 & 1 & 2 & 3 & 4 & 5 & 1 & $2^{\star}$ & 3 & $4^{\star}$ & 5 \\
\hline $\begin{array}{l}\text { Compliance } \\
\text { Well controlled asthma† } \\
\text { Attack of wheezing } \\
\text { Attack of breathlessness } \\
\text { Excess cough }\end{array}$ & $\begin{array}{r}86 \\
96 \\
23 \\
7 \\
27\end{array}$ & $\begin{array}{l}95 \\
86 \\
19 \\
12 \\
24\end{array}$ & $\begin{array}{l}98 \\
75 \\
20 \\
12 \\
26\end{array}$ & $\begin{array}{l}89 \\
83 \\
26 \\
13 \\
22\end{array}$ & $\begin{array}{l}76 \\
65 \\
18 \\
10 \\
23\end{array}$ & $\begin{array}{l}93 \\
97 \\
20 \\
11 \\
21\end{array}$ & $\begin{array}{l}93 \\
84 \\
17 \\
10 \\
24\end{array}$ & $\begin{array}{l}96 \\
92 \\
20 \\
10 \\
26\end{array}$ & $\begin{array}{r}79 \\
70 \\
15 \\
9 \\
21\end{array}$ & $\begin{array}{r}76 \\
82 \\
15 \\
9 \\
22\end{array}$ & $\begin{array}{l}92 \\
80 \\
17 \\
14 \\
37\end{array}$ & $\begin{array}{l}99 \\
62 \\
22 \\
17 \\
38\end{array}$ & $\begin{array}{l}84 \\
86 \\
23 \\
11 \\
33\end{array}$ & $\begin{array}{l}99 \\
75 \\
32 \\
25 \\
43\end{array}$ & $\begin{array}{l}82 \\
58 \\
23 \\
19 \\
43\end{array}$ \\
\hline
\end{tabular}

*The two schools closest to coal stockpile. Schools coded 1 and 2 in exposed area were those from which the original complaints were received. + Proportion with well controlled asthma. $¥$ Child who coughs more than other children.

Table 4 Composite respiratory symptom prevalence (\%) in study areas

\begin{tabular}{lccc}
\hline $\begin{array}{l}\text { Respiratory } \\
\text { symptoms }\end{array}$ & $\begin{array}{l}\text { Control } \\
\text { area 1 } \\
(n=637)\end{array}$ & $\begin{array}{l}\text { Control } \\
\text { area 2 } \\
(n=616)\end{array}$ & $\begin{array}{l}\text { Exposed } \\
\text { area } \\
(n=426)\end{array}$ \\
\hline C+ B+ W+ & $7 \cdot 1$ & $5 \cdot 4$ & $12 \cdot 7 \dagger$ \\
C+ B- W- & $7 \cdot 1$ & $6 \cdot 2$ & $13 \cdot 6 \dagger$ \\
C+ B- W+ & $5 \cdot 0$ & 3.9 & $4 \cdot 2$ \\
C+ B+ W- & $1 \cdot 1$ & $1 \cdot 1$ & $3 \cdot 0$ \\
C- B+ W+ & $1 \cdot 3$ & $1 \cdot 5$ & $1 \cdot 6$ \\
C- B- W- & $69 \cdot 1$ & $71 \cdot 3$ & $54 \cdot 2 \dagger$ \\
C- B- W+ & $4 \cdot 6$ & 3.4 & 3.5 \\
C- B+ W- & 0.0 & 0.8 & 0.9 \\
\hline
\end{tabular}

$\mathrm{C}=$ excess cough during last 12 months; $\mathrm{B}=$ severe attack of breathlessness at any time; $W=$ attack of wheezing at any time. + or - indicates symptom present or absent.

*Total do not make $100 \%$ as about $6 \%$ of children reported a cough but not in preceding 12 months.

†Exposed $v$ control 1 or $2, \mathrm{p}<0.01$.

of the respiratory symptoms in the exposed group (table 2). Thus in the exposed zone significantly more children had been diagnosed by a doctor as having asthma and their asthma was less likely to be well controlled. In contrast, factors known to predispose to asthma, such as one or both parents having asthma or the presence of any allergy, were not higher in the exposed area. Specific questions about the incidence of hay fever, eczema, or croup were also not different between areas. Comparison of response rates and respiratory indices in individual schools showed that between school response rates were comparable within each of the three areas (table 3). This comparison also showed that the higher prevalence of respiratory indices in the exposed area did not result from increased reporting in a single school.

In all areas there were expected associations to be found; thus respiratory symptoms were less common in girls than boýs (relative risk (95\% confidence interval) for ever diagnosed asthma $0.64 \quad(0.50$ to 0.82$)$; wheezing $0.71(0.56$ to 0.90$))$. The exception was increased cough in the preceding 12 months which showed no relation with gender. Maternal asthma showed a more significant association with breathlessness or wheezing or absenteeism from school due to these symptoms than paternal asthma.

There was no significant difference in either the duration of wheezing or episodes of breathlessness or their age of onset between the three study areas. Neither was the onset of wheezing or breathlessness more common in the exposed area in the three years before the survey which corresponded to the period of coal importation. The symptoms of recent cough, wheeze, and breathlessness occurred together in $12.7 \%$ of children in the exposed area, which is significantly increased compared with the other areas (table 4 ). The symptom of recent cough but without associated wheezing or breathlessness also occurred more often in the exposed area.

All conditioning environmental factors (infection, weather, exercise, smoke, cigarette smoking, emotion, and household dust) were reported as significantly more likely to provoke wheezing or coughing in the children in the exposed area. High prevalence figures for respiratory indices were reported for the exposed children when the parent considered coal dust exposure was associated with symptoms (ever diagnosed asthma $42 \cdot 2 \%$; attack of breathlessness, $41 \cdot 2 \%$; excess cough $75.5 \%$ ). Of parents in all study areas who did not report excess childhood cough as a problem, however, about $80 \%$ indicated that conditioning factors (including coal dust) were not likely to provoke this symptom. Hospital admissions at any age due to respiratory disease were increased when the parent considered coal dust exposure a problem $(17 \cdot 3 \%$ compared with $2 \cdot 6 \%$ ). Analysis of variance showed no significant difference in peak flows between the two groups categorised by parental opinion on coal dust exposure. There was no increased risk of parental asthma which ever parental opinion was held about the respiratory risk to children of coal dust exposure.

\section{SEVERTTY OF RESPIRATORY SYMPTOMS}

Severity of respiratory symptoms was assessed in relation to school days lost in the preceding 12 months with cough, wheeze, or breathlessness. The frequency of school absenteeism because of respiratory symptoms was higher in four of five schools in the exposed area compared with the 10 schools in the control areas. Table 5 shows the distribution of school days lost due to cough, wheeze or breathlessness for the three groups. Lost days due to respiratory symptoms are more common in schools in the exposed area. Hospital admission for wheezing or breathlessness in the year preceding the questionnaire was slightly over $2 \%$ of children for the exposed area and

Table 5 Distribution of school days lost in preceding 12 months due to respiratory symptoms. Values are \%

\begin{tabular}{lccc}
\hline $\begin{array}{l}\text { School days } \\
\text { lost }\end{array}$ & $\begin{array}{l}\text { Control } \\
\text { area 1 }\end{array}$ & $\begin{array}{l}\text { Control } \\
\text { area } 2\end{array}$ & $\begin{array}{l}\text { Exposed } \\
\text { area }\end{array}$ \\
\hline None & $65 \cdot 1$ & $64 \cdot 1$ & $52 \cdot 5$ \\
$1-5$ & $23 \cdot 2$ & $24 \cdot 0$ & $26 \cdot 3$ \\
$6-20$ & $8 \cdot 6$ & $9 \cdot 9$ & $15 \cdot 2$ \\
$>20$ & $3 \cdot 1$ & $2 \cdot 0$ & $6 \cdot 0$ \\
\hline
\end{tabular}


Table 6 Respiratory variables in control and exposed groups in relation to passive smoking. Values are \% (number)

\begin{tabular}{|c|c|c|c|c|c|c|}
\hline \multirow[b]{2}{*}{ Variable } & \multicolumn{2}{|c|}{ Control area 1} & \multicolumn{2}{|c|}{ Control area 2} & \multicolumn{2}{|l|}{ Exposed area } \\
\hline & $\begin{array}{l}\text { Non- } \\
\text { smoking }\end{array}$ & Smoking & $\begin{array}{l}\text { Non- } \\
\text { smoking }\end{array}$ & Smoking & $\begin{array}{l}\text { Non- } \\
\text { smoking }\end{array}$ & Smoking \\
\hline $\begin{array}{l}\text { Ever diagnosed asthma } \\
\text { Ever diagnosed bronchitis } \\
\text { Ever diagnosed croup } \\
\text { Well controlled asthma* } \\
\text { Maternal asthma } \\
\text { Paternal asthma } \\
\text { Attack of wheezing } \\
\text { Attack of breathlessness } \\
\text { Excess cought }\end{array}$ & $\begin{array}{r}17 \cdot 4(276) \\
8 \cdot 8(274) \\
11 \cdot 6(275) \\
88 \cdot 2(51) \\
7 \cdot 7(260) \\
6 \cdot 0(267) \\
17 \cdot 3(271) \\
8 \cdot 4(273) \\
20 \cdot 1(278)\end{array}$ & $\begin{aligned} 16 \cdot 9(396) \\
12 \cdot 6(389) \\
15 \cdot 7(388) \\
78 \cdot 1(73) \\
4 \cdot 1(363) \\
8 \cdot 6(383) \\
23 \cdot 0(374) \\
12 \cdot 9(379) \\
28 \cdot 6(396)\end{aligned}$ & $\begin{array}{l}13 \cdot 1(267) \\
7 \cdot 8(256) \\
10 \cdot 2(256) \\
94 \cdot 3(35) \\
4 \cdot 8(249) \\
3 \cdot 9(255) \\
15 \cdot 4(253) \\
8 \cdot 1(259) \\
20 \cdot 0(265)\end{array}$ & $\begin{array}{r}16 \cdot 7(406) \\
10 \cdot 6(396) \\
13 \cdot 6(396) \\
85 \cdot 0(80) \\
6 \cdot 8(384) \\
6 \cdot 6(376) \\
18 \cdot 7(380) \\
11 \cdot 9(380) \\
25 \cdot 1(394)\end{array}$ & $\begin{array}{r}22 \cdot 1(140) \\
15 \cdot 4(136) \\
12 \cdot 7(134) \\
83.9(31) \\
6.9(131) \\
8 \cdot 3(132) \\
23 \cdot 3(129) \\
17 \cdot 2(128) \\
36 \cdot 3(138)\end{array}$ & $\begin{array}{r}20 \cdot 7(334) \\
16 \cdot 9(326) \\
14 \cdot 8(324) \\
67 \cdot 5(80) \\
7 \cdot 3(300) \\
7 \cdot 3(313) \\
25 \cdot 3(312) \\
19 \cdot 9(317) \\
41 \cdot 6(334)\end{array}$ \\
\hline $\begin{array}{l}\text { Ever admitted to hospital for } \\
\text { respiratory symptoms } \\
\text { School absent for respiratory }\end{array}$ & $7 \cdot 8$ (268) & $10 \cdot 7(385)$ & $3 \cdot 1(256)$ & $3 \cdot 6(386)$ & $9 \cdot 0(134)$ & $8 \cdot 0$ (327) \\
\hline $\begin{array}{l}\text { symptoms in last year } \\
\text { Allergies } \\
\text { Drugs prescribed }\end{array}$ & $\begin{array}{l}30 \cdot 8(260) \\
15.9(258) \\
15 \cdot 3(281)\end{array}$ & $\begin{array}{l}37 \cdot 7(371) \\
17 \cdot 4(350) \\
12 \cdot 5(392)\end{array}$ & $\begin{array}{l}30 \cdot 5(253) \\
13.9(244) \\
12 \cdot 3(261)\end{array}$ & $\begin{array}{r}38 \cdot 8(376) \\
12 \cdot 0(367) \\
9 \cdot 8(400)\end{array}$ & $\begin{array}{l}46 \cdot 0(126) \\
17 \cdot 7(130) \\
18 \cdot 2(137)\end{array}$ & $\begin{array}{l}48 \cdot 0(321) \\
11 \cdot 8(297) \\
17 \cdot 5(331)\end{array}$ \\
\hline
\end{tabular}

^Proportion of those with asthma in whom it is well controlled. †Child who seems to cough more than other children.

Absent for one or more days.

$\$ 70 \%$ of all drugs were for asthma.

control 1. A lower proportion of children were admitted to hospital with respiratory symptoms in control area $2(<0.5 \%)$. There was a lower proportion of children in the exposed group who had well controlled asthma compared with either control group (table 2).

\section{STRATIFICATION ANALYSES}

For each of the socioeconomic differences between the areas (table 1) the groups were divided into two strata for that variable and the between group comparisons repeated. Table 6 illustrates this approach for passive smoking. Children of smokers do have more respiratory symptoms than the children of non-smokers, but for both smoking and non-smoking subgroups there remains an increased incidence of respiratory symptoms in the area exposed to dust. This pattern of exposed versus control group differences was consistent for each of these analyses.

\section{REGRESSION ANALYSIS AND CONTROL FOR} CONFOUNDING FACTORS

A more sophisticated method of controlling for the background differences between areas is to perform a multiple logistic regression. This constructs odds ratios for each zone adjusted for multiple confounders. The respiratory outcome variables fall into three main groups, relating to any history of respiratory disease, existence of current problems, and severity. Multiple logistic regression models were constructed for one outcome variable from each of these groups: ever diagnosed asthma, wheezing, and absenteeism from school. The odds ratios and $\chi^{2}$ values were calculated for each potential risk factor separately; these variables were candidates for inclusion in multiple logistic regression models if the $\chi^{2}$ value was significant at the $10 \%$ level. Significant risk factors fell into several broad groupings: variables relating to allergies, family history of respiratory disease, household pets, passive smoking, dampness, and socioeconomic status, in addition to sex (boy), geographical zone (exposed zone), and age. Within each of these groups the main factors were identified using stepwise logistic regression. For example, the main factor among variables relating to allergies was the presence of any allergy; adding variables for the presence of specific allergies (for example hay fever, eczema) into the model did not significantly reduce the deviance. Among the passive smoking variables, whether there were any smokers in the household was a dominant factor; incorporating the number of smokers or the type (pipe/cigarette) did not significantly reduce the deviance. Responses to subsidiary questions often had missing values; for wheezing and ever diagnosed asthma the presence of rising damp had a marginally larger $\chi^{2}$ value than the general variable for the presence of any damp, but it was not chosen because it had missing values for over half the data set. Having thus identified the dominant risk factors in each group, stepwise logistic regression was used to select a model from these variables. Finally, each remaining variable in the data set was entered in turn to the model and the model revised by stepwise methods: if adding it significantly reduced the deviance, or removing a variable already in the model did not significantly increase the deviance, the model was revised.

Table 7 details the resulting models. For ever diagnosed asthma, other allergies, parental history, sex (boy), and socioeconomic status (renting rather than owner occupier) are the dominant risk factors; going to school in the exposed zone, smoking, dampness, and household pets, though significant when considered in isolation, do not have odds ratios significantly different from unity after adjusting for known confounders, and their inclusion in the model does not significantly alter the odds ratios for other variables. A similar model resulted for wheeze, but passive smoking is an additional significant risk factor for wheeze. The model for recent absenteeism from school due to cough wheeze or breathlessness, however, which we take as a measure of severity, is different: sex and parental history are now omitted and other health problems are a risk factor; going to school in the exposed zone enters as a dominant risk factor with an odds ratio of $1 \cdot 59$, which is significantly greater than 
Table 7 Adjusted odds ratio for risk indices from multiple logistic regression

\begin{tabular}{|c|c|c|}
\hline Variable & $\begin{array}{l}\text { Odds } \\
\text { ratio }\end{array}$ & $\begin{array}{l}95 \% \\
\text { Confidence } \\
\text { interval }\end{array}$ \\
\hline \multicolumn{3}{|l|}{ Wheezing $(n=1272)$} \\
\hline Any allergy & $4 \cdot 95$ & 3.52 to 6.96 \\
\hline Either parent with asthma & $2 \cdot 41$ & 1.60 to 3.62 \\
\hline Sex (girl) & 0.66 & 0.49 to 0.89 \\
\hline Father unemployed & 1.44 & 1.05 to 1.97 \\
\hline Passive smoking & 1.44 & 1.05 to 1.98 \\
\hline School in exposed zone & 1.37 & 0.98 to 1.91 \\
\hline \multicolumn{3}{|c|}{$\begin{array}{l}\text { School absenteeism }{ }^{\star} \text { due to cough, wheezing, or breathlcssness } \\
(n=1391)\end{array}$} \\
\hline Any allergy & $2 \cdot 72$ & 2.02 to 3.66 \\
\hline School in exposed zone & 1.59 & 1.23 to 2.04 \\
\hline Passive smoking & $1 \cdot 33$ & 1.05 to 1.68 \\
\hline Other health problems & $1 \cdot 36$ & 1.05 to 1.75 \\
\hline Mother unemployed & $1 \cdot 29$ & 1.02 to 1.63 \\
\hline \multicolumn{3}{|l|}{ Ever diagnosed asthma $(n=1409)$} \\
\hline Any allergy & $6 \cdot 27$ & 4.49 to 8.74 \\
\hline Mother has diagnosed asthma & $2 \cdot 68$ & $1 \cdot 38$ to $5 \cdot 20$ \\
\hline Father has diagnosed asthma & 1.97 & 1.09 to 3.55 \\
\hline Sex (girl) & $0 \cdot 70$ & 0.52 to 0.95 \\
\hline Rented home & $1 \cdot 37$ & 1.00 to 1.87 \\
\hline School in exposed area & $1 \cdot 25$ & 0.88 to 1.76 \\
\hline
\end{tabular}

^More than one day in preceding 12 months.

unity after adjusting for confounding effects about which we have information $(95 \%$ confidence interval $1 \cdot 23$ to $2 \cdot 04$ ).

Peak flow can be predicted well from the child's height, age, and sex. Zone and other respiratory disease risk factors do not improve the predictions. The seasonal distribution of respiratory problems is the same for exposed and control zones (that is, a slight increase in autumn/winter). The predictive power of the logistic regression models is poor, reflecting the fact that much of the variation between children in the occurrence and severity of respiratory disease is unexplained by the measured variables.

\section{AIR POLLUTION DATA}

A number of problems were associated with the study, in particular the loss of samples due to damage of the gauges from vandalism. Only a few results were then available for the study. It is difficult to draw full conclusions from so few results; however, it appears that the exposed area has appreciable pollution from airborne dust.

The monitor in the exposed area showed consistently higher loading than either of the control schools for comparable sampling periods. A large percentage of the insoluble fraction in the exposed area consisted of combustible matter, which may consist of unburnt coal, partially combusted coal, or oil and other organic matter (combustible matter in exposed area $39.2 \%$; control $1,6.3 \%$; control $2,6.5 \%$ ). It was not possible to carry out further analysis on these samples to positively identify the components due to the destructive nature of

Table 8 Summary of British Standard dust deposit gauge results in exposed area (December 1990 to November 1991)

\begin{tabular}{|c|c|c|c|c|c|}
\hline \multirow[b]{2}{*}{ Location } & \multirow[b]{2}{*}{$\begin{array}{l}\text { No of } \\
\text { samples }\end{array}$} & \multicolumn{4}{|c|}{ Undissolved deposited matter $\left(\mathrm{mg} / \mathrm{m}^{2} /\right.$ day $)$} \\
\hline & & $\begin{array}{l}\text { Mean }(S D) \\
\text { annual amount }\end{array}$ & Median & Minimum & Maximum \\
\hline $\begin{array}{l}1 \\
2\end{array}$ & $\begin{array}{l}12 \\
13\end{array}$ & $\begin{array}{l}148 \cdot 8(50 \cdot 5) \\
109 \cdot 4(45 \cdot 8)\end{array}$ & $\begin{array}{l}151 \cdot 4 \\
200 \cdot 9\end{array}$ & $\begin{array}{l}45 \cdot 3 \\
44 \cdot 0\end{array}$ & $\begin{array}{l}245 \cdot 9 \\
200 \cdot 9\end{array}$ \\
\hline
\end{tabular}

$\star$ Based on four weekly sampling periods. the initial test. A higher $\mathrm{pH}$ was recorded in samples from the exposed area than in the controls, but this may result from other local influences not necessarily related to coal. The variable nature of the weather over each sampling period of four weeks meant that it was not possible to positively categorise the sources of the material deposited within the gauges. Detailed results of the standard deposit gauge analyses for the three areas are available on request.

The local authority summary of deposited dust results during the preceding year (December 1990-November 1991) in two sites in the exposed area is shown in table 8 . For three of the sampling periods dust deposit gauge results showed average deposition values over $200 \mathrm{mg} / \mathrm{m}^{2} /$ day.

\section{Discussion}

Questionnaire surveys are widely used to study respiratory symptoms in children. Such questionnaires have been shown to yield reproducible answers, ${ }^{18}$ but the validity of a survey is dependent on the response rate achieved. The excellent response rate to the questionnaire of over $90 \%$ is similar to that obtained by the Southampton survey (which had used a similar format) and was better and more uniform across the groups and schools than several other recently published studies of childhood respiratory symptoms (Birmingham schoolchildren 69 and $84 \%$; Munich and Leipzig children 76 and 88\%; Swiss children $74 \%$; and the Monkton coking works study $78 \% 81920)$. A higher response rate increases the confidence in the data and so does the comparability of the responses between the schools. One of the schools in the exposed area has been the subject of much press speculation and thus responses from this index school which was closest to the coal terminal might have biased the results. In the event this school was no different from the remaining four in the exposed zone for many of the respiratory indices. Another possible source of bias could have occurred if more children had been off sick in the exposed zone and been missed by the survey; the even response rate suggests this is also unlikely, but had it occurred, correction would have increased the differences observed. The three areas were studied in parallel over a three month period so that any climatic or seasonal influences were the same for each area.

We were concerned that parents in the exposed zone might simply answer yes indiscriminately. It is therefore reassuring that the reported incidence of hay fever and croup were not different between the zones and that when a child was reported to have, for example, an increased cough within the last year, further questions as to the relation of the symptom to other provoking factors were consistent across the groups, suggesting that these were genuine symptoms resulting in genuine morbidity.

The level of respiratory symptoms in our two control areas are comparable with those reported elsewhere ${ }^{316}$ and suggest that 
Liverpool in general is no different from other cities in the UK. The increased level of respiratory symptoms in the exposed zone shows up on each of the analyses and despite controlling for all the potential confounding variables, including socioeconomic factors. There is a possibility that other socioeconomic factors might be operating - for example, standards of hygiene. There can be no doubt, however, that the children in this area do have an excess of respiratory morbidity.

Hospital admissions due to respiratory disease were not significantly increased in the exposed compared with the control zones. Hospital admissions in the exposed area due to respiratory disease were increased, however, when the parent considered coal dust exposure to be a health problem. This suggests that parental attribution of cause and effect may have followed the development of symptoms and illness (decided by a hospital doctor and not a parent) rather than it being a phenomenon of parental overreporting of symptoms. The severity of symptoms may be greater in children with asthma after exposure to air pollution thus increasing the likelihood of hospital admission. There is evidence that the effect on child health in the exposed area is sufficient to cause an increase in the number of school days lost due to respiratory symptoms. Wheezing and asthma are recognised as important causes of school absence. Absenteeism in the control areas was comparable with that reported in a study from Nottingham. ${ }^{21}$

Before the study the parents had labelled the respiratory problems as asthma. We observed an increased incidence of diagnosed asthma, but the most striking statistical correlations between the zones was for the symptom 'recent cough'. Recent cough without wheeze or breathlessness is markedly higher in the exposed children as well as the symptom complex of cough, wheeze, and breathlessness that is typical of asthma. This could imply that the major effect of air pollution is to cause an increase in coughing, possibly as a direct effect of inhaling an increased burden of dust. It is reassuring that the peak flows measured in each of our study areas were normal, but it should be remembered that measurements were only performed on children when they were at school and thus by definition well. It is established that workers in dusty jobs are likely to develop a cough productive of phlegm, but that this 'simple bronchitis' occurs without airflow limitation. ${ }^{22}$ The confounding influence of cigarette smoking in miners has resulted in some controversy, but in general coal dust is not held to be a cause of airway obstruction even in those miners who have simple bronchitis. All the studies of dust and occupation are of adults, however, and there are no longitudinal data about the effect of increased cough (associated with other markers of morbidity such as absence from school) on children. The growing and maturing lung may handle a dust burden differently from the adult lung and moreover these children are exposed 24 hours a day, whereas workers are only exposed for eight. It is established that children of smoking parents fare less well and the magnitude of the effect between our study areas suggests that the local environment in north Liverpool is at least as important as passive smoking for these children.

This study was cross sectional in design and although we can confidently state that there is a respiratory problem in the exposed area, we cannot attribute the problem to a specific cause. There is an increased dust pollution problem in the area which is relatively recent and which provides a simple, straightforward explanation. Moreover, the effect on cough in particular fits with the hypothesis that this is the result of an increased burden of inhaled dust. Further studies are needed to confirm or deny the connection.

The other obvious pollutant to blame is the grain terminal, but this has been present for many years and the grain handling is almost entirely by enclosed processes. There are some animal feeds arriving intermittently on the docks which are not well handled and could provide a potential source of allergenic pollution that could provoke asthma. Asthma was the weakest correlate in the survey, however; we did not detect increased hospital admissions for asthma and the symptoms complex of wheeze and breathlessness was not increased. In dust samples analysed there were plentiful amounts of combustible, carbonaceous material.

Our findings of an increase in symptoms in an area with a high dust pollution load is consistent with other reports published since our study began. A study from South Wales reported an increased diagnosis of asthma by general practitioners when a new surface coal mine began operation. ${ }^{23}$ It is not clear whether this was really asthma or whether the general practitioners were overdiagnosing the symptom of cough. A Swiss study looked at the respiratory health of primary schoolchildren in three areas and noted that respiratory symptoms were highest in the area with the highest level of suspended particulates in the air and that they were independent of levels of nitrogen and sulphur oxides. ${ }^{8}$ The Monkton coking works study from the north of England and the Munich/Leipzig study from Germany found similar results. In the former it is interesting that the effects were much more prominent in children than adults. ${ }^{19}{ }^{20}$ Lastly, in the USA a longitudinal study of schoolchildren showed changes in peak expiratory flow and symptoms over time, which varied in response to changing levels of airborne particulates. ${ }^{24}$

If air pollution is causing these effects it would seem to be a chronic effect (which may be cumulative), but which is not sufficient to lead to an increased prevalence of severe attacks requiring admission to hospital. Although symptoms and morbidity factors such as time off school are increased there is no evidence of serious damage. All these studies support the hypothesis that the increased respiratory symptoms in children in north Liverpool have been exacerbated by the dust 
pollution. The annual average deposition rate of undissolved matter shown in table 7 for one of the two sites in the exposed area is above the likely nuisance guidelines of $130 \mathrm{mg} / \mathrm{m}^{2} /$ day. It is important not to overinterpret a cross sectional study, however; we can state confidently that there is a child health problem, but further studies are needed to determine if pollution is the cause.

The Steering Committee is grateful for the support and assistance of the headteachers and school staff who were involved with this project. The questionnaire format was designed by $\mathbf{M}$ Ken Jones of the Liverpool School of Tropical Medicine medical illustration unit. Several people have supported and advised on the project since its inception. We are especially to Dr David Heaf for his advice and support throughout the study, and to Dr M Klenka for assistance in facilitating the Wallasey control survey. The help offered by health visitors in taking measurements at the school surveys was greatly appreciated and also the time made available by the staff of Sefton and Wirral Environmental Health Departments. The study was partly supprironmental Health Departments. The Borough Council and the South Sefton Health Authority. Asthma Steering Committee: M Smith (Chair), M Pearson, B Brabin, E Dunne, $M$ de Felice, and $Q$ Syed.

1 Britton J. Asthma's changing prevalence [Editorial]. BMf 1992; 304: 857-8.

2 Anderson HR. Is the prevalence of asthma changing? Arch Dis Child 1989; 64: 172-5.

3 Ninan TK, Russell D, Russell G. Increasing prevalence of respiratory symptoms and atopy in Aberdeen school children: evidence from two surveys. $B M F$ 1992; 304: 873-5.

4 Ayres JG, Pansari S, Weller PH, et al. A high incidence of asthma and respiratory symptoms in 4-11 year old children. Respir Med 1992; 86: 403-7.

5 Lunn JE, Knowelden J, Handyside AJ. Patterns of respiratory illness in Sheffield infant school children. British fournal of Preventive and Social Medicine 1967; 21: 7-16.

6 Sobral HR. Air pollution and respiratory diseases in children in Sao Paulo, Brazil. Soc Sci Med 1989; 29: 929-64.

7 Colley JRT, Brasser LJ. Chronic respiratory diseases in children in relation to air pollution. Copenhagen: World Health Organisation, 1980 (EURO reports and studies No 28)

8 Braun-Fahrlander C, Ackermann-Liebrich U, Schwartz J, Braun-Fahrlander $C$, Ackermann--Lebrich $M$, Wir pollution and respiratory symptoms in preschool children. Am Rev Respir Dis 1992; 145: 42-7.

9 Ware JH, Ferris BG Jr, Dockery DW, Spengler JD, Stram DO, Speizer FE. Effects of ambient sulfur oxides and suspended particles on respiratory health of preadolescent suspended particles on respiratory health of pread
children. Am Rev Respir Dis 1986; 133: 834-42.

10 Wang JY, Hsiue TR, Chen HI. Bronchial responsiveness in an area of air pollution resulting from wire reclamation. arch Dis Child 1992; 67: 488-90.

11 Dockery DW, Speizer FE, Stram DO, Ware JH, Spengler JD, Ferris BG. Effects of inhalable particles on respiratory health of children. Am Rev Respir Dis 1989; 139: 587-94

12 Finn R. John Bostock, hay fever and the mechanism of allergy. Lancet 1992; 340: 1453-5.

13 Andrae S, Axelson O, Bjorksten B, Fredriksson $M$, Kjellman NIM. Symptoms of bronchial hyperreactivity and ash in relation to environmental factors. Arch Dis Child 1988; 63: 473-8.

14 Sultz H, Feldman JG, Schlesinger ER, Mosher EM. An effect of continued exposure to air pollution on the incieffect of continued exposure to air pollution on the incidence of chronic childhood

15 Crombie HE. Rimrose Estate and Merlin Stevedores. Coa dust, health and the community [Dissertation]. Liverpool: University of Liverpool, 1990

16 Clifford RD, Radford $M$, Howell JB, Holgate ST Prevalence of respiratory symptoms among 7 and 11 year old schoolchildren and association with asthma. Arch Dis Child 1989; 64: 1118-25.

17 Godfrey S, Kamburoft PL, Nair NIR, et al. Spriometry, lung volumes and airway resistance in normal children lung volumes and airway resistance in normal

18 Brunekreef B, Groot B, Rijken B, Hoek G, Steenbekkers A Boer de A. Reproducibility of childhood respiratory symptom questions. Eur Respir f 1992; 5: 930-5.

19 Mutius E von, Fritzsch C, Weiland SK, Roll G, Magnussen $H$. Prevalence of asthma and allergic disorders among children in united Germany: a descriptive comparison. BMF 1992; 305: 1395-9.

20 Bhopal R, Moffat S, Phillimore P, Foy C. The Monkton coking works study. The impact of an industry on the health of a community. A report to South Tyneside Metropolitan Borough Council. Newcastle upon Tyne: Metropolitan Borough Council. Newcas

21 Hill RA, Standen PJ, Tattersfield AE. Asthma, wheezing and school absence in primary schools. Arch Dis Child 1989; 64: 246-51.

22 Morgan WKC. Industrial bronchitis. In: Morgan WKC Seaton A, eds. Occupational lung diseases. Philadelphia: Saunders, 1984

23 Temple JMF, Sykes A. Asthma and open-cast mining. $B M$ 1992; 305: 396-7.

24 Arden Pope C, Dockery DW. Acute health effects of PM10 pollution on symptomatic and asymptomatic children. Am Rev Respir Dis 1992; 145: 1123-8. 